\title{
EFEITO DA SOMATOTROPINA SOBRE A CICATRIZAÇÃO DE FERIDAS CUTÂNEAS, EM RATOS ${ }^{1}$
}

\author{
Luciana de Oliveira Marques dos Santos ${ }^{2}$ \\ Maria de Lourdes Pessole Biondo Simões ${ }^{3}$ \\ Ana Paula Bächtold Machado ${ }^{4}$ \\ Gladyston Roberto Matioski Filho ${ }^{4}$ \\ Patrícia Cristina Endo ${ }^{4}$ \\ Giselle Rauen Gruen ${ }^{5}$ \\ Vanessa Rejane Cipriani $^{5}$ \\ Lismary Deforville Mesquita ${ }^{6}$
}

\begin{abstract}
Santos LOM, Biondo-Simões MLP, Machado APB, Matioski Filho GR, Endo PC, Gruen GR, Cipriani VR, Mesquita LD. Efeito da somatotropina sobre a cicatrização de feridas cutâneas, em ratos. Acta Cir Bras [serial online] 2002 Jul-Ago;17(4). Disponível em URL: http://www.scielo.br/acb.

RESUMO - A somatotropina, além do efeito anabolizante, age no processo de cicatrização acelerando a formação local de tecido de granulação, síntese e deposição de colágeno, quando administrada por via subcutânea. Objetivo: Avaliar o efeito da somatotropina sobre a cicatrização de feridas cutâneas, em ratos. Métodos: Utilizaram-se 53 ratos Wistar, machos, com idade média de 145,19 dias e peso inicial médio de 287,72 g, divididos em dois grupos: controle $(\mathrm{n}=26)$ que recebeu 1,2 ml/dia de água destilada pela via subcutânea e experimento $(n=27)$ que recebeu $0,2 \mathrm{UI} / \mathrm{kg} / \mathrm{dia}$ de somatotropina humana pela mesma via. Fez-se uma ferida cutânea no dorso do animal, que diariamente era medida, procedendo-se ao final do experimento o cálculo de contração da ferida. Os tempos de aferição foram 3, 7 e 14 dias, quando de 9 animais de cada grupo, coletou-se sangue para dosagem bioquímica de proteínas plasmáticas e ressecou-se a ferida para estudo histológico. À microscopia avaliou-se: epitelização, reação inflamatória local, tecido de granulação, neovascularização e fibrose. Resultados: O cálculo de contração da ferida, nos 3 tempos de aferição, não demonstrou diferenças entre os grupos controle e experimento. Na dosagem bioquímica encontrou-se diminuição das proteínas totais $(\mathrm{p}=0,007)$ e aumento da relação albumina/globulina $(\mathrm{p}=0,03)$ no $14^{\circ}$ dia no grupo controle, enquanto o grupo experimento manteve-as constantes. Na avaliação histológica observou-se significante aumento da fibrose no $7^{\circ}$ dia no grupo experimento ( $\left.p<0,0001\right)$. Conclusões: A somatotropina mantém constantes a relação albumina/globulina e as proteínas totais plasmáticas no $14^{\circ}$ dia, além de intensificar a fibrose cicatricial quando utilizada durante 7 dias.
\end{abstract}

DESCRITORES - Somatotropina. Cicatrização de feridas.

\section{INTRODUÇÃO}

A somatotropina é um hormônio anabólico secretado pela hipófise anterior, que atua na maioria dos processos metabólicos do organismo, exercendo efeitos diversos ${ }^{1}$ quando administrada via subcutânea $^{1,2}$. Esse hormônio atua diretamente estimulando a diferenciação de precursores celulares em células mais maduras e promove o crescimento por estimular a secreção de IGF-I no fígado, o qual atua como um

1- Trabalho realizado na Disciplina de Experimentação em Clínica e Cirurgia do Curso de Medicina da Faculdade Evangélica do Paraná.

2- Professora Adjunta da Disciplina de Experimentação em Clínica e Cirurgia do Curso de Medicina da Faculdade Evangélica do Paraná.

3- Professora Titular da Disciplina de Experimentação em Clínica e Cirurgia do Curso de Medicina da Faculdade Evangélica do Paraná.

4- Monitores da Disciplina de Experimentação em Clínica e Cirurgia do Curso de Medicina da Faculdade Evangélica do Paraná.

5- Alunas do quinto ano do Curso de Medicina da Faculdade Evangélica do Paraná.

6- Professora Auxiliar da Disciplina de Anatomia e Fisiologia Patológica do Curso de Medicina da Faculdade Evangélica do Paraná. 
agente endócrino causando o crescimento de tecidos periféricos ${ }^{1,3}$.

O processo de cicatrização envolve a migração de células inflamatórias, a síntese de tecido de granulação, a deposição de colágeno e de proteoglicanos e a maturação da cicatriz, estando associada à intensa remodelação ${ }^{3}$.

Os fibroblastos da pele apresentam receptores de somatotropina, a qual induz a produção e a secreção de IGF I estimulando a replicação dos fibroblastos por meio de mecanismos autócrinos e parácrinos. ${ }^{1}$

Durante a cicatrização, a somatotropina pode acelerar a formação local de tecido de granulação, o depósito de colágeno ${ }^{2}$ e influir no metabolismo dos fibroblastos aumentando a síntese da matriz, o que inclui os colágenos tipos I e II ${ }^{3}$. Ainda, aumenta a síntese e diminui a degradação de proteínas, aumenta a mobilização de lipídeos, diminui a oxidação de glicose e aumenta o armazenamento de glicogênio. ${ }^{3}$

Em estudos recentes, a somatotropina aumentou a resistência das feridas cutâneas quando administrada no tempo do trauma ${ }^{5,6}$. Porém, tem-se discutido se a somatotropina tem papel fisiológico na reparação tecidual, uma vez que as feridas de pessoas com deficiência de somatotropina cicatrizaram normalmente ${ }^{6}$. Percebeu-se que o fator liberador da somatotropina não estimula a deposição de colágeno no tecido de granulação, contudo, acelera a maturação deste colágeno. ${ }^{6}$

Outros estudos observando o efeito da somatotropina em ratos queimados mostraram que a sua administração não tinha qualquer efeito. ${ }^{7}$

Sabendo-se das ações da somatotropina no processo de cicatrização primária da pele, questionou-se sua ação na cicatrização por segunda intenção e definiu-se o objetivo do presente estudo: estudar a ação da somatotropina sobre a cicatrização, por segunda intenção, de feridas cutâneas de ratos.

\section{MÉTODOS}

Para a realização deste estudo obedeceu-se à Lei Federal 6.638 e às orientações do Colégio Brasileiro de Experimentação Animal.

Utilizaram-se 53 ratos convencionais (Rattus norvegicus albinus, Rodentia mammalia) Wistar, machos, com idade de 144 a 147 dias e peso inicial médio de 287,72 gramas, provenientes do biotério da FEPAR

Os animais foram alojados no Biotério da Faculdade Evangélica do Paraná, onde o macro-ambiente era semicontrolado, com foto-período de 12 horas, temperatura ambiental média de $21,6^{\circ} \mathrm{C}(\mathrm{DP} \pm 1,06)$.
A luminosidade, a intensidade de ruído e a umidade relativa do ar eram as do ambiente geral. As gaiolas foram colocadas todas à mesma distância do solo $(80 \mathrm{~cm})$. Os ratos recebiam cuidados diários, água potável e ração padrão para a espécie à vontade.

Todos os animais foram marcados e pesados no primeiro dia do experimento e no dia da aferição, para posterior análise da variação ponderal.

Procedeu-se à anestesia inalatória com éter etílico a $98 \%$ para pesagem, bem como para todos os procedimentos dolorosos e/ou situações de estresse.

Dividiu-se a amostra, aleatoriamente, em dois grupos, conforme o tratamento proposto:

- grupo controle: com 26 animais que receberam $1,2 \mathrm{ml} /$ dia de água destilada $(\mathrm{AD}) \mathrm{e}$

- grupo experimento: com 27 animais que receberam 0,2 U/kg/dia de somatotropina humana (Somatotropin SIGMA) diluída em 1,2ml de AD.

A medicação de cada grupo foi administrada por via subcutânea, na região posterior do tórax, sempre no mesmo horário do dia (18 horas).

No primeiro dia do experimento demarcou-se a área da ferida com molde metálico circular de $2 \mathrm{~cm}$ de diâmetro, e produziu-se a ferida cutânea retirando-se a pele e a tela subcutânea, expondo-se a fáscia dorsal.

Diariamente as feridas eram limpas com soro fisiológico a $0,9 \%(\mathrm{SF})$, impressas em papel fino e ocluídas com curativo. A partir das impressões das feridas, ao final do experimento realizou-se o cálculo matemático de contração da ferida, convertendo-se o valor absoluto em porcentagem.

Para aferição, foram submetidos à eutanásia, 9 animais de cada grupo no $3 .^{\circ}, 7^{\circ}$ e $14 .^{\circ}$ dia do experimento. Previamente à eutanásia, procedeu-se punção cardíaca destinada à coleta de sangue. As dosagens bioquímicas de albumina e proteínas totais séricas foram realizadas por método colorimétrico, e após calculouse a relação albunima/globulina (A/G).

A seguir ressecava-se a ferida, com $0,5 \mathrm{~cm}$ da margem, distendia-se o tecido em papel filtro e fixavase em formalina tamponada. As peças retiradas eram enviadas para análise histológica corando-se os cortes pela Hematoxilina e Eosina.

Na microscopia avaliou-se o grau de epitelização, a intensidade da reação inflamatória local, o tipo de reação inflamatória conforme a célula predominante, a presença de tecido de granulação, a neovascularização e a fibrose. Os dados eram coletados em ficha própria e avaliados conforme se descreve no Quadro 1. 
Quadro 1 - Protocolo de análise microscópica das feridas cutâneas.

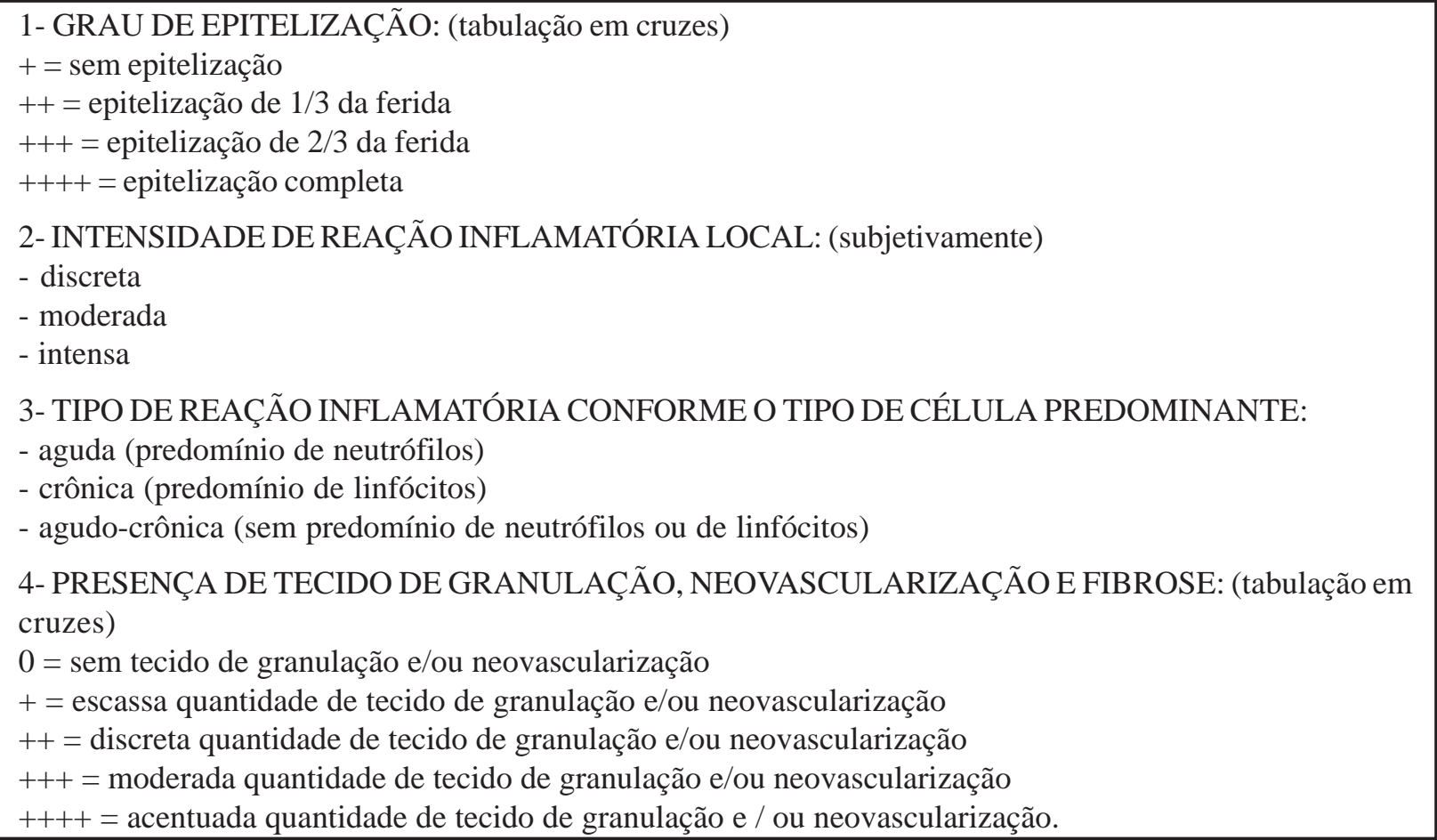

Para análise estatística da contração da ferida utilizou-se o teste não-paramétrico Mann-Whitney (software "Primer of Biostatistics") e o teste paramétrico t de Student. Para avaliação das proteínas séricas realizou-se Análise de Variância (ANOVA), os testes t de Student e Mann-Whitney. Na microscopia empregou-se o teste Exato de Fisher (software "Epi-Info") para amostras independentes. Adotou-se $\mathrm{p}=0,05$ ou 5\% como nível para rejeição da hipótese de nulidade.

\section{RESULTADOS}

\section{1- Alterações ponderais}

Na correlação entre peso inicial e final observouse perda de peso nos dois grupos em todos os tempos de aferição; contudo a maior perda de peso foi encontrada no grupo experimento, no $3^{\circ}$ dia $(\mathrm{p}<0,0001)$.

\section{2- Avaliação de contração da ferida cutânea}

Comparando-se os grupos controle e experimento em cada tempo de aferição, não se observou diferenças com relação à contração média e nem percentual $\left(\mathrm{p}_{3^{\circ} \text { dia }}\right.$ $\left.=0,40, \mathrm{p}_{7^{\circ} \mathrm{dia}}=0,376 \mathrm{e} \mathrm{p}_{14^{\circ} \mathrm{dia}}=0,145\right)$. Através do gráfico de evolução da contração da ferida (Figura 1) observa-se que a área da ferida diminuiu com o passar do tempo de lesão.

\section{3- Dosagem de proteínas séricas}

Constatou-se diferença significante entre os grupos controle e o experimento no $14^{\circ}$ dia. No grupo

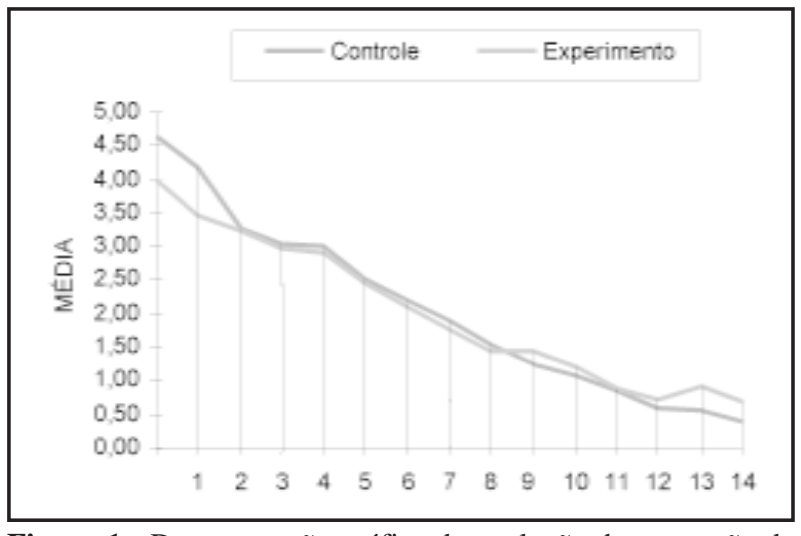

Figura 1 - Demonstração gráfica da evolução da contração da ferida nos grupos controle e experimento.

controle houve diminuição das proteínas totais e aumento da relação $\mathrm{A} / \mathrm{G}$, enquanto que no grupo experimento os valores mantiveram-se constantes (proteínas totais $\mathrm{p}=0,007$ e relação $\mathrm{A} / \mathrm{G} \mathrm{p}=0,030$ ).

\section{Avaliação microscópica da ferida cutânea}

\section{a) Grau de epitelização:}

No $3^{\circ}$ e $7^{\circ}$ dia nenhum dos grupos apresentava ferida epitelizada. No $14^{\circ}$ dia constatou-se epitelização de $1 / 3$ da ferida, em $25 \%$ do grupo controle e em $22,2 \%$ do experimento, porém sem diferença significante $(\mathrm{p}=0,58)$. 


\section{b) Intensidade de reação inflamatória:}

No $3^{\circ}$ dia a reação inflamatória nas feridas era de intensidade moderada nos dois grupos. No $7^{\circ}$ dia era intensa em $100 \%$ nas do grupo controle e em $77,8 \%$ nas do grupo experimento. No $14^{\circ}$ dia eram moderadas em $87,5 \%$ das feridas do grupo controle e em $77,8 \%$ nas do gruo experimento, mas sem diferenças significantes $\left(\mathrm{p}_{7^{\circ} \text { dia }}=0,235\right.$ e $\left.\mathrm{p}_{14^{\circ} \text { dia }}=0,529\right)$.

\section{c) Tipo de reação inflamatória}

No $3^{\circ}$ dia a reação inflamatória mostrava-se agudocrônica em 77,8\% das feridas do grupo controle e em $88,9 \%$ das do experimento. No $7^{\circ}$ dia era agudo-crônica em $100 \%$ das feridas dos dois grupos, modificado-se no $14^{\circ}$ dia, quando a porcentagem das feridas com reação inflamatória do tipo crônica aumentou para $33,5 \%$ no grupo controle e para $33,3 \%$ no experimento. Contudo as diferenças entre os grupos, não foram significantes $\left(\mathrm{p}_{3^{\circ} \mathrm{dia}}=0,50\right.$ e $\left.\mathrm{p}_{14^{\circ} \mathrm{dia}}=0,626\right)$.

\section{d) Avaliação do tecido de granulação e neovascularização:}

As porcentagens de tecido de granulação e neovascularização foram às mesmas em cada grupo. No $3^{\circ}$ dia, ambas foram de intensidade moderada em $77,8 \%$ do grupo controle e 55,6\% do grupo experimento. No $7^{\circ}$ dia, ambas evoluíram para acentuadas em $44,4 \%$ do controle e $66,7 \%$ das do experimento. Contudo, regrediram no $14^{\circ}$ dia quando ambas mostravam-se em quantidades moderadas em $75 \%$ do grupo controle e escassas em 55,6\% do experimento. Apesar das diferentes porcentagens observadas, estas não foram significantes $\left(\mathrm{p}_{3^{\circ} \text { dia }}=0,31, \mathrm{p}\right.$ $7_{7^{\circ} \text { dia }}=0,318$ e $\mathrm{p}_{14^{\circ} \text { dia }}=0,217$ ).

\section{e) Avaliação de fibrose:}

Todas as feridas dos animais de ambos os grupos apresentaram grau discreto de fibrose no $3^{\circ}$ dia de aferição. No $7^{\circ}$ dia, $100 \%$ das feridas do grupo controle mostraram grau discreto enquanto que em $88,9 \%$ das do grupo experimento exibiam grau intenso (Figura 2), sendo esta diferença significante $(\mathrm{p}<0,0001)$.

No $14^{\circ}$ dia a fibrose foi semelhante nos dois grupos, e graduada como moderada em $75 \%$ dos animais do grupo controle e $77,8 \%$ do experimento $(\mathrm{p}=0,45)$.

\section{DISCUSSÃO}

Segundo alguns autores a administração de somatotropina provoca, em ratos, ganho de peso por ter efeito anabólico ${ }^{1,2}$. A cirurgia gera um estado catabólico que leva à perda de peso no pós-operatório ${ }^{1}$. Para outros, a somatrotopina tem atividade anabólica limitada, em ratos, com pituitária funcionalmente normal ${ }^{7}$, não provocando ganho de peso ${ }^{6,7}$. O presente estudo mostrou perda de peso no terceiro dia de uso de somatotro-

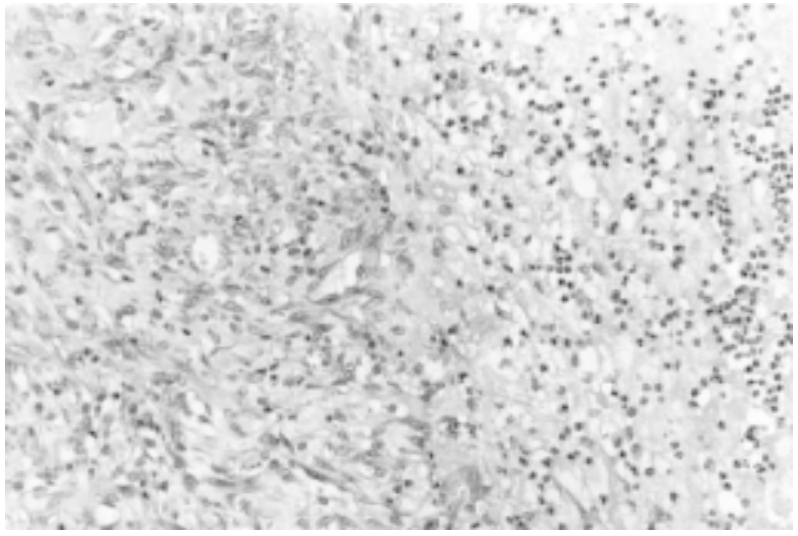

Figura 2 - Fotomicrografia de corte histológico de ferida obtido do grupo experimento mostrando, no $7 .^{\circ}$ dia do estudo, intenso grau de fibrose representado por fibras colágenas desorganizadas e núcleos de fibroblastos. Vê-se neste corte infiltrado inflamatório rico em linfócitos.

pina, que pode ter sido ocasionada pelo estado catabólico pós-operatório.

Relata-se que a aceleração do processo de reparação de feridas seria devido ao efeito direto da somatotropina sobre os fibroblastos ou pela estimulação do IGF1 que está presente no tecido de cicatrização ${ }^{6}$. Neste estudo não se observou diferença relacionada à contração da ferida cutânea quando se utilizou somatotropina.

Alguns autores afirmam que a somatotropina aumenta a síntese e diminui a degradação de proteínas ${ }^{3}$, porém outros autores não encontraram evidências de que a somatotropina tivesse algum efeito sobre o nível de albumina sérica ${ }^{7}$. Nesse estudo constatou-se que o uso de somatotropina durante 14 dias, em comparação ao controle, gerou menor variação das proteínas totais e manteve constante a relação $\mathrm{A} / \mathrm{G}$, indicando maior quantidade de globulina sérica, proteína plástica envolvida no processo de cicatrização e na formação de colágeno. Quando as proteínas nos tecidos diminuem, as proteínas séricas podem atuar como fonte para rápida reposição.

As doses ideais de somatotropina para estimular a formação de tecido de granulação variam entre 0,2 e 0,7 UI, uma vez que com doses superiores não se observam tais efeitos ${ }^{2}$. Ainda, sua potência seria maior por administração local do que por sistêmica. ${ }^{2}$ Certos estudos mostram que a somatotropina produz tecido de granulação com maior concentração de hidroxiprolina ${ }^{6}$; contudo em nosso estudo o tecido de granulação e a neovascularização foram maiores no sétimo dia de cicatrização independente da administração de somatotropina.

Utilizando-se altas doses de somatotropina ocorreria diminuição da síntese de colágeno e da cicatrização, porém em menores doses o efeito seria inverso, isto devido à presença de receptores de somatotropina nos fibroblastos ${ }^{2}$ Nesse experimento encontrou-se intenso 
grau de fibrose no sétimo dia, indicando que nesta etapa da cicatrização, a somatotropina, na dose utilizada, poderia aumentar a síntese e deposição de colágeno.

Os resultados deste estudo parecem promissores em relação à formação de colágeno e ao suporte protéico plasmático. Contudo, sabendo-se que o mesmo utilizou ratos sadios e que as maiores dificuldades de cicatrização por segunda intenção ocorrem em organismo com carências nutricionais, sugerindo-se novos estudos para avaliar os efeitos da somatotropina em condições nutricionais adversas.

Apesar do modelo de estudo em ratos ser considerado adequado para entender o processo de cicatrização em humanos, deve-se lembrar que completo entendimento da cicatrização cutânea humana somente será obtido a partir de estudos na mesma espécie.

\section{CONCLUSÃO}

A somatotropina mantém constante a relação albumina/globulina e proteínas totais plasmáticas no $14^{\circ}$ dia, além de intensificar a fibrose cicatricial quando utilizada durante 7 dias.

\section{REFERÊNCIAS}

1 - Jorgensen PH. Growth hormone, skin and wound healing: experimental studies in the rat. APMIS 1997; 105(supl.72): 1-494.

2- Rasmussen LH, Garbarsch C, Schuppan D, Moe D, HorslevPedersen K, Gottrup F, Steenfos H. Dose response profiles of human growth hormone in subcutaneous wound chambers in rats. Eur J Surg 1995; 161:157-62.

3 - Biondo-Simões MLP, Pante ML, Macedo VL,Garcia RF, Boell P, Moraes THC. O hormônio de crescimento e a concentração de colágeno na cicatriz de feridas cutâneas de ratos. Acta Cir Bras 2000; 15(supl.3):78-82.

4- Skottner A, Arrhenius-Nyberg V, Kanje M, Fryklund L. Anabolic and tissue repair functions of recombinant insulin-like growth factor I. Acta Pediatr Scand 1990; 367(supl.):63-6.

5 - Jorgensen PH, Bang C, Andreassen T, Flyvbjerg A, Orskov H. Dose-response study of the effect of growth hormone on machanical properties of skin graft wounds. J Surg Res 1995; 58:295-301.

6- Garrel DR, Gaudreau P, Zhang L, Reeves I, Brazeau P. Chronic adminstration of growth hormone-releasing factor increases wound stregth and collagen maturation in granulation tissue. $\mathbf{J}$ Surg Res 1991; 51:297-302.

7- Belcher HJCR e Ellis H. Somatropin and wound healing after injury. J Clin Endocrinol Metab 1990; 70(4):939-43.

Santos LOM, Biondo-Simões MLP, Machado APB, Matioski Filho GR, Endo PC, Gruen GR, Cipriani VR, Mesquita LD. Effect of somatotropin on skin wound healing in rats. Acta Cir Bras [serial online] 2002 Jul-Aug;17(4). Available from URL: http://www.scielo.br/acb.

ABSTRACT - Somatotropin, in addition to having an anabolizing effect, also acts on the healing process by accelerating the local formation of granulation tissue and collagen synthesis and deposition when administered subcutaneously (SC). Objective: To evaluate the effect of somatotropin on skin wound healing in rats. Methods: Fifty-three male Wistar rats aged on average 145.19 days and weighing $287.27 \mathrm{~g}$ at the beginning of the study were divided into two groups: control $(\mathrm{n}=26)$ receiving $1.2 \mathrm{ml} /$ day distilled water $(\mathrm{SC})$, and experimental $(\mathrm{n}=27)$ receiving $0.2 \mathrm{IU} / \mathrm{kg} / \mathrm{day}$ human somatotropin (SC). A skin wound was produced in the dorsum of the animal and measured daily, and wound contraction was calculated at the end of the experiment. At 3, 7 and 14 days, blood was collected from 9 animals in each group for biochemical determination of plasma proteins and the wound was resected for histological study. Epithelialization, local inflammatory reaction, granulation tissue, neovascularization and fibrosis were evaluated microscopically. Results: The calculation of wound contraction at the 3 checking times dis not show significant differences between the control and experimental groups. The biochemical determinations showed an decrease in total proteins $(\mathrm{p}=0.007)$ and a increase in the albumin/gobulin ratio $(\mathrm{p}=0.03)$ in the control group on the $14^{\text {th }}$ day of the study, whereas remain stable in the experimental group. Histological evaluation showed a significant increase in fibrosis in the experimental group on the $7^{\text {th }}$ day $(p<0.0001)$. Conclusion: Somatotropin remain stable the albumin/globulin ratio and total plasma proteins on the $14^{\text {th }}$ day, and also intensified cicatricial fibrosis when used for 7 days.

KEY WORDS - Somatotropin. Wound healing.

\section{Endereço para correspondência:}

Luciana de Oliveira Marques dos Santos

Rua Gastão Câmara, 694/1202

80730-300 Curitiba - PR
Conflito de interesse: nenhum Fonte de financiamento: nenhuma

Data do recebimento: 03/05/2002

Data da revisão: 18/06/2002 Data da aprovação: 01/07/2002 